\title{
Tecer a vida em tempos de pandemia: narrativas e aprendizagens de jovens universitários camponeses
}

\section{Weaving life in pandemic times: narratives and learning from young university peasants}

${ }^{1}$ Idalina Souza Mascarenhas Borghi ismborghi@ufrb.edu.br

${ }^{2}$ Nanci Rodrigues Orrico

${ }^{3}$ Maricleide Pereira de Lima Mendes

\section{RESUMO}

Este artigo intenciona promover reflexões sobre vivências e aprendizagens de jovens estudantes da Licenciatura em Educação do Campo (UFRB), no período da pandemia da Covid-19. Nesse sentido, buscou-se discutir quais estratégias são utilizadas pelos jovens na construção de condições para produzir a vida em tempos de pandemia, identificando implicações econômicas, sócio/culturais e políticas nos modos de ser e resistir, que já se apresentam como características destes estudantes. O texto emerge como uma das ações do projeto"Entre desafios e aprendizagens: repercussões da pandemia para a vida de jovens da Educação do Campo-CETENS/UFRB”, vinculado ao grupo de pesquisa Educação e Diversidade (GEPED/UFRB). Ratificando a crença de que entendemos como relevante a valorização das falas dos jovens, no sentido de compreendermos seus anseios, dilemas e modos de existir e resistir, validamos as narrativas dos jovens universitários a partir de um viés metodológico (auto)biográfico, de escuta e acolhimento. Para isso, foram realizadas rodas de conversas e entrevistas narrativas em ambiente virtual com estudantes integrantes do projeto, em um movimento de escuta sensível para o que dizem, de modo a nos dar subsídios de enfrentamento das questões da permanência na Universidade, no período pós-pandemia. A partir da pesquisa desenvolvida, algumas conclusões apontam para a riqueza das aprendizagens construídas pelos jovens no enfrentamento das adversidades provocadas pela pandemia e revelam a necessidade de novos estudos que valorizem os estudantes como produtores de conhecimentos em suas vivências cotidianas, permitindo-nos repensar as experiências pedagógicas e as estratégias de permanência destes jovens na Universidade.

Palavras-chave: Juventude camponesa. Educação do Campo. Pandemia do Covid-19. Permanência Universitária.

\section{ABSTRACT}

This article intends to promote reflections on experiences and learning of young students of the Rural Education Degree (UFRB) in the period of the Covid-19 pandemic. In this sense, we sought to discuss which strategies are used by the students in the construction of conditions to continue living and being productive in times of pandemic, identifying economic, socio/cultural and political implications in the ways of being and resisting, which are already presented as characteristics of these students. The text emerges as one of the actions of the project "Between challenges and learning: repercussions of the pandemic for the lives of young people in Rural Education - CETENS/UFRB", linked to the research group "Education and Diversity" (GEPED/UFRB). Ratifying the belief that we understand the importance and relevance of the students' speeches, in the sense of understanding their desires, dilemmas, and ways of existing and resisting, we validate the narratives of young university students from a methodological (auto) biographical perspective, through listening and welcome. For this purpose, groups of conversations and narrative interviews were conducted in a virtual environment with students participating in the project, in a way of sensitive listening to what they say, in order to give us support for facing the issues of staying at the University, in the post-pandemic. From the research developed, some conclusions point to the great value of learning built by the students in facing the adversities caused by the pandemic and revealed the need for new studies 
that recognize the students as producers of knowledge in their daily experiences, allowing us to rethink the teaching experiences and the strategies for the permanence of these young students at the University.

Keywords: Peasant youth. Rural Education. Covid-19 Pandemic. University Permanence

\section{INTRODUÇÃO}

Objetivando discutir sobre as vivências, experiências e aprendizagens que as juventudes camponesas universitárias têm vivenciado no período de pandemia da Covid-19, este artigo propõe uma reflexão sobre vivências e aprendizagens de jovens estudantes da Licenciatura em Educação do Campo com habilitação em Ciências da Natureza e Matemática da Universidade Federal do Recôncavo Baiano (CETENS/UFRB ${ }^{4}$ ), no decorrer do processo de tessitura da vida no campo em um contexto pandêmico.

Ressalta-se que este texto desdobra-se como ação de um projeto aprovado no âmbito do Edital 01/2020 - PIBIC 2020/2021 (UFRB) e vinculado ao grupo de pesquisa Educação e Diversidade (GEPED/UFRB). O referido projeto, intitulado "Entre desafios e aprendizagens: repercussões da pandemia para a vida de jovens da Educação do Campo-CETENS/UFRB”, busca compreender singularidades e ações cotidianas vivenciadas por estudantes da Educação do Campo durante a pandemia da Covid-19, especialmente no que diz respeito às estratégias criadas por eles na construção da condição juvenil diante dos desafios impostos pelo contexto atual. O entendimento destas vivências é considerado importante por oferecer subsídios à comunidade acadêmica para o tratamento de questões ligadas à aprendizagem e permanência na Universidade, no período de retorno destes estudantes à vida universitária pós-pandemia.

Intencionamos, no decorrer deste artigo, refletir sobre como os jovens universitários moradores de áreas camponesa vem produzindo a vida em tempos de pandemia e quais aprendizagens e ensinamentos podemos apreender dos seus relatos. Na dinâmica dos jovens campesinos estudantes das licenciaturas em Educação do Campo, evidencia-se um quadro de vivências cotidianas marcadas pela resistência e persistência para se inserir socialmente, driblando os efeitos das desigualdades sociais que afetam diretamente as suas condições de produção de vida e, consequentemente, a permanência no campo e na universidade. Nesse sentido, buscamos o entendimento dos desafios e resistências vivenciados por estes jovens em tempos de pandemia e privilegiamos uma investigação sob um viés (auto)briográfico, como forma de valorizar e acolher as angústias, enfrentamentos e anseios vividos pelos estudantes neste período.

\section{REFLEXÕES SOBRE JUVENTUDES E EDUCAÇÃO DO CAMPO NO CENÁRIO DA COVID-19}

O diálogo sobre juventudes camponesas e Educação do Campo, em um cenário de pandemia do Covid-19, aponta para dilemas de uma crise que não se inicia com a chegada do coronavírus, mas que com ela se intensifica, afetando profundamente as pessosas das classes populares.

As assimetrias nas condições de acesso aos meios de proteção, assistência à saúde e condições básicas de produção de existência, revela uma sociedade estruturada na lógica do capital, que prioriza a economia, mesmo que, para isso, tenha que sacrificar a defesa da vida humana. Isso faz com que exista uma grande contradição entre as demandas essenciais de enfrentamento da Covid-19 e as condições de possibilidades das pessoas em situação de pobreza, no que concerne à observância dos cuidados de prevenção recomendados. Neste sentido,

4 A Universidade Federal do Recôncavo da Bahia possui sete Centros de Ensino, sendo que os cursos de Licenciatura em Educação do Campo (com Habilitação em Matemática e Ciências da Natureza), cujos estudantes são colaboradores nesta pesquisa, são ofertados no Centro de Ensino de Ciência e Tecnologia em Energia e Sustentabilidade (CETENS), localizado no município de Feira de Santana/BA. 
seguir as normas da Organização Mundial da Saúde (OMS), para fins de prevenção ao vírus, não é possibilidade para todos. Como afima Santos (2020), as recomendações da Organização Mundial da Saúde (OMS) sugerem ter sido feitas pensando nas pessoas das classes médias e altas, que são uma pequena fração da população mundial.

Em sociedades com mais justiça social e maior participação do Estado em políticas sociais emergenciais, é evidente que a exposição das pessoas aos riscos de morte seria bem menor. Nesta linha de reflexão, Bourdieu (2007), aponta que: "Não há espaço, em uma sociedade hierarquizada, que não seja hierarquizado e que não exprima as hierarquias e as distâncias sociais [...]” (p. 162). Isso reporta à percepção de Borghi ${ }^{5}$ (2013), ao afirmar que a posse de maior ou menor capital econômico e cultural define os espaços e os bens públicos e privados que as pessoas podem acessar. Portanto, antes do isolamento social provocado pelo coronavírus, os grupos sociais considerados pobres ou abaixo da linha da pobreza, já vivenciavam a exclusão de espaços, bens e serviços, legitimados pela cruel injustiça social.

Entendemos que pensar sobre a complexidade desse momento histórico inclui também o desafio de fortalecer o debate sobre como os jovens camponeses estão resistindo e construindo a sua condição juvenil no campo, o que inclui pensar nas vivências, aprendizagens, saberes e expectativas que alimentam suas lutas pela defesa da vida. Nesse intuito, cabe situar as perspectivas de juventude e Educação do Campo que balizam este estudo.

\section{JUVENTUDE CAMPONESA E EDUCAÇÃO DO CAMPO}

Nesta pesquisa, entendemos que viver a condição juvenil na diversidade do ser jovem, historicamente, tem se configurado como um processo de construção social diretamente implicado com questões socioeconômicas, políticas e culturais. Sabemos que os jovens, em uma sociedade, não se constituem em um grupo homogêneo. Dayrell (1999) conceitua juventude como, ao mesmo tempo, uma condição social e um tipo de representação, entendendo que as idealizações que procuram unificar os sentidos dos movimentos sociais da juventude tendem a ser ultrapassadas pelo contínuo movimento da realidade (CARRANO, 2007).

Na mesma direção, Pais (2003) entende que: “A juventude é uma categoria socialmente construída, formulada no contexto de particulares circunstâncias econômicas, sociais e políticas, uma categoria sujeita a modificar-se ao longo do tempo" (p.37). Neste sentido, este estudo configura-se a partir do entendimento que os jovens das classes populares e, especificamente, os que vivem no campo, têm uma singularidade na maneira de produzir a sua condição juvenil, o que está diretamente relacionado com o acesso aos espaços enquanto possibilidade gerada pelo capital econômico e social que as pessoas dispõem.

Dialogando com essa percepção, os estudos de Kammsetzer e PalombiniII (2017, p.284), nos mostram que: “ A diversidade das experiências dos jovens tem relação com a própria diversidade social que constitui os lugares”. Apesar das juventudes camponesas não serem um grupo homogêneo, já que há uma diversidade de locais em que habitam e, consequentemente, das suas especificidades percebe-se sentimentos, desafios e situações comuns entre eles, relacionados especialmente à vida em comunidade, destacando-se o da falta de políticas públicas específicas para este segmento da sociedade.

É na trama dos processos históricos de violação de direitos essenciais, que os grupos, historicamente penalizados pela ausência de políticas públicas e pelo racismo estrutural, neste caso as juventudes, reagem nas periferias, no campo e na cidade e criam estratégias de resistência. Concordando com Nogueira (2017): "São nesses territórios negros e periféricos que a força do capital e do Estado fincam suas mais perversas raízes. Porém, são nesses territórios que surgem expressões de resistências culturais e políticas, sobretudo por parte da juventude [...]“ (Nogueira, 2017, p. 5)

5 A tese de Borghi(2013), intitulada “Uma margem outra: itinerância de jovens das classes populares na Educação Superior” aborda as injustiças sociais vivenciadas por jovens egressos da Educação de Jovens e Adultos ao adentrarem a Universidade. 
Essas expressões de resistências estão muito presentes nos movimentos das populações do campo ${ }^{6}$ e,de acordo com Caldart (2019), a Educação do Campo surge da articulação de lutas de diversos sujeitos camponeses, que se organizam para reagir a negação de direitos, que historicamente lhes foram negados, e se associam na luta por escolas públicas “[...] no campo, e que possam se construir como escolas do campo (p.59)”. Não se trata da luta de pessoas, mas de coletivos dialogando, com suas singularidades, em torno de lutas comuns. É por considerar a relevância dessa articulação nas lutas dos sujeitos que vivem e trabalham no campo, que a autora chama atenção para as três raízes originárias ${ }^{7}$ da Educação do campo: i) a luta dos sujeitos coletivos,ii)aagricultura camponesa ,iii) a concepção emancipatória da educação.

Entendemos que, durante a pandemia do Covid-19, mesmo sem a possibilidade de viver a universidade, presencialmente, os licenciandos da LEdoC continuam seus percursos formativos, nas variadas maneiras de tecer a vida e resistir a tantas formas de negação de direitos. Isso, sem dúvidas, pode se constituir como elemento fundante para a Universidade se aproximar dos estudantes, aprender com suas experiências e reinventar as políticas de permanência, visto que formar educadores e educadoras para atuar na Educação do Campo diz respeito, também, ao fortalecimento da luta por permanência e pelo direito de construir condições para viver com dignidade a condição juvenil.

\section{PERCURSO METODOLÓGICO: POTENCIALIDADES DA PESQUISA (AUTO) BIOGRÁFICA}

Ao assumirmos a pesquisa qualitativa como abordagem balizadora do nosso estudo, optamos pelo viés de uma investigação assentada nos princípios da (auto)biografia por reconhecer que é preciso ampliar estudos que escutem os jovens camponeses, licenciandos da LEdoC, operando com suas subjetividades e que possam servir, também, para que os estudantes do campor reflitam e elaborem seus dilemas, especialmente no contexto contemporâneo marcado por intensos processos de angústias e incertezas, forjadas pelas circunstâncias que a pandemia tem demandado.

Salienta-se, então, nesta pesquisa, a importância dos relatos dos jovens universitários do campo como instrumento de investigação, mas também de formação e valorização das suas singularidades para a construção de novas pedagogias. Reconhecemos a importância do que eles têm a dizer e a relevância das suas vozes sobre os modos como constroem suas vidas, como forma, inclusive, de favorecer situações para que estes jovens possam: “ [...] metabolizar as experiências contraditórias ou dissociativas e modificar, no sentido de uma nova figuração de si, as representações que os orientam na sua apreensão das situações e das pessoas”, como salienta Delory-Momberger (2014, p.127) ao defender a utilização da pesquisa (auto)biográfica no trabalho com as juventudes.

O estudo busca, desse modo, voltar o olhar para o cotidiano vivenciado, neste período de pandemia, pelos jovens $^{8}$ universitários que cursam as licenciaturas em Educação do Campo do CETENS (UFRB), utilizando, como

6 Entendemos por Populações do campo os agricultores familiares, os extrativistas, os pescadores artesanais, os ribeirinhos, os assentados e acampados da reforma agrária, os trabalhadores assalariados rurais, os quilombolas, os caiçaras, os povos da floresta, os caboclos e outros que produzam suas condições materiais de existência a partir do trabalho no meio rural.

7 Referendada nestas raízes históricas, a Educação do Campo tem se afirmado a partir da defesa de uma educação que respeite à diversidade dos sujeitos e dos coletivos sociais, étnicos, raciais e de gênero; o desenvolvimento de políticas de formação de profissionais da educação em consonância com as especificidades das escolas do campo; o fortalecimento da identidade da escola do campo, por meio de projetos políticos pedagógicos e outros projetos pedagógicos direcionados ao atendimento das necessidades dos estudantes camponeses, dentre outros princípios queconstituem-se direito garantido no Decreto 7.352e que orienta a formação dos licenciandos da LEDdoC, na UFRB.

8 Sobre os jovens selecionados para serem participantes da pesquisa e que irão metabolizar essas experiências vividas, contamos com a colaboração de 9 estudantes matriculados no Curso de Licenciatura em Educação do Campo (CETENS-UFRB), identificados, neste estudo, por suas iniciais, e com idades que variam entre 18 e 29 anos. Os estudantes colaboradores são moradores de diferentes municípios do Estado da Bahia:Iraquara, Irará, Feira de Santana, Irecê, Ibotirama, Itaguaçu da Bahia e Ibipeba. 
dispositivos de pesquisa ${ }^{9}$, rodas de conversas e entrevistas narrativas desenvolvidas com estes estudantes em ambiente virtual, de modo a entender seus diferentes mecanismos de aprendizagens, de vivências culturais, de construções identitárias, de desafios econômicos e sociais, de engajamento nas suas comunidades e de empoderamento.

\title{
5 NARRATIVAS JUVENIS: ENSINAMENTOS E APRENDIZAGENS EM TEMPOS DE COVID-19
}

\author{
“ Isso de querer ser exatamente \\ o que a gente é
}

ainda vai nos levar além. ”

Paulo Leminsky (2013, p.140)

A epígrafe, com um poema de Leminsky, veio à tona no momento de escuta das narrativas dos jovens da LEdoC da UFBB/CETENS. São vozes juvenis mescladas por muitos sentimentos - ansiedade, força, medo, engajamento, coragem, dúvidas-e ávidas em participar de uma atividade na qual eles podiam ser quem são, ansiosos para retomar os contatos com a Universidade e serem escutados na inteireza das suas identidades e peculiaridades de jovens moradores do campo, que lutam pelo direito de acessar e concluir um curso superior, apesar de todos os desafios que surgem no caminho. E, na autenticidade dos seus relatos, podemos perceber que é reafirmando as suas identidades e sendo exatamente quem são que eles irão além, como disse o poeta.

Reconhecendo a importância do que eles têm a dizer e a relevância das suas vozes sobre os modos como estão construindo suas vidas durante a pandemia, os nove jovens participantes do estudo, ao narrarem suas vivências, permitiram que adentrássemos, de forma respeitosa, nos seus mundos, partilhando suas experiências. Seus relatos foram dispostos, neste artigo, em três eixos temáticos: vivências, aprendizagens e expectativas.

A identificação das vivências feitas a partir da análise das narrativas trouxe informações relevantes sobre a forma como os jovens estão vivenciando o distanciamento social necessário neste período. Como outros participantes da pesquisa, ISA afirmou: “Fico em casa, só saio quando é necessário”. Entretanto, ao falar de como estão vivenciando a pandemia, alguns outros relatos chamaram a atenção:

Eu fico dentro de casa, é um momento doloroso, mas apesar disso procuro refletir a vida e valorizar a família e cada momento que tenho, dando conta de ajudar meu filho nas atividades da escola, coisa que não fazia, o que me levou a compreender a ausência que faço na vida do meu filho (DBB).

Apesar de perceber que a maioria dos estudantes está obedecendo as orientações de distanciamento e isolamento social, ficam evidente as angústias sentidas, neste contexto, principalmente pelas jovens que são mães. Estas estudantes já têm um histórico de resiliência, amplificado pelas condições de injustiças a que são expostas. Normalmente, no campo, não podem contar com creches e precisam se dividir entre as demandas da casa, filhos, universidade, sustento da família, algumas contando com a ajuda do companheiro e familiares, outras enfrentando o desafio solitário de assumir múltiplas tarefas e responsabilidades. Muitas sucubem e acabam desistindo do curso.

9 Os dispositivos de pesquisa foram escolhidos por possibilitar uma atenção às vivências juvenis e uma escuta respeitosa das experiências dos jovens participantes deste estudo. Nesse sentido, optamos em utilizar três eixos para nortear as rodas de conversas e entrevistas narrativas (vivências, aprendizagens e expectativas) e, a partir destes eixos de discussão, foi estimulada a livre narrativa, com um mínimo de interferência dos mediadores, conforme orientam os referenciais teóricos de Connelly e Clandinin (1990),Jovchelovitch e Bauer (2010) e Schutze (2010). 
Estas e outras situações adiversas reveladas nas narrativas dos jovens expressam as singularidades, na maneira de produzir a condição juvenil. Este fato fica evidente, quando, diante do quadro de ausência do Poder Público em situações emergenciais, como a vivenciada na pandemia, nota-se que alguns jovens estudantes assumiram a liderança em suas comunidades, como podemos perceber na fala de CSD, quando este diz que não tem conseguido estudar, “[...] porque a demanda da comunidade é grande, estou auxiliando as pessoas da comunidade no cadastro do auxílio emergencial”. Também JGB relata que vem participando em ações em prol da comunidade. “Ajudo a associação, faço parte do Conselho Estadual e esse momento me fez perceber o quanto esse Conselho é importante para a comunidade.”

A experiência pandêmica, trouxe diversas limitações, mas é admirável ver como os jovens (re)inventam a vida e potencializam redes de solidariedades, rediscubrindo o valor das organizações sociais, o que impulsiona o ativismo juvenil e a busca de altenativas para reagir e afrontar as consequências da ausência do poder público e dos direitos negados aos povos do campo. Essa dinâmica de militância e produção da condição juvenil, é potencializada por vulnerabilidades já existentes, mas que a crise expõe. Como disse Santos (2020): “ O vírus é capaz de infectar qualquer um, mas prevaleceu entre os mais vulneráveis, os mais pobres”. Para este autor, o sistema neoliberal tem produzido uma crise permanente e, em muitas realidades, o estado de crise se transformou em justificativa para explicar a retirada de direitos adquiridos, como tem ocorrido no Brasil, em que a crise finaceira tem sido usada para legitimar os cortes das políticas púbicas sociais(saúde, educação, previdência social) e a degradação dos salários.

Contudo, os jovens camponeses encontram alternativas para driblar a ineficiência do poder público e organizam redes de solidariedade para não deixar que sejam intensificadas, ainda mais, as injustiças sociais contra as pessoas que não tiveram acesso à escolaridade e não tinham as condições necessárias para responder às exigências de cadastro do auxilio emergencial. Essa atitude solidária reafirma a importância do acesso de jovens do campo a uma proposta educativa que dialogue com suas realidades, visto ser perceptível o modo como eles vão se apropriando dos saberes adquiridos na Universidade, dando significado a essas aprendizagens na interação com os saberes construídos nas suas comunidades e ampliando as condições de entre ajuda e produção da existência no campo.

Nesse viés, o engajamento social e a resistência são potencializados na pandemia. CSD relata que, neste momento de pandemia, houve um crescimento na organização social dos moradores.

Eu aprendi muito sobre solidariedade na comunidade. Aqui existe solidariedade, a Associação de Moradores está mais organizada, as pessoas estão mais ativas e, num âmbito geral, as pessoas estão umas procupadas com as outras (CSD).

É possível enxergar, nas suas falas, a relação que estes jovens estabelecem com o local em que vivem, com as pessoas da comunidade e com as experiências vividas na coletividade. LPG conta que está trabalhando também com esse sentimento de apoiar a comunidade e se unir para evitar as consequências que o coronavírus pode trazer aos moradores da sua localidade. Ela diz:“[...]eu estou trabalhando nas barreiras sanitárias, [...] eu estou trabalhando dois dias da semana. Nas barreiras, ficamos controlando quem pode entrar na comunidade e medindo a temperatura."Já JGB narra a insegurança que vivenciou: "no inicio a comunidade entrou em pânico, fechou a entrada e só saia e entrava pessoas autorizadas".

Evidenciam-se, no que diz respeito às aprendizagens, que, em grande parte das narrativas, os jovens passam a dar mais valor ao que tinham: suas famílias, trabalhos, as redes desolidariedades. Reconhecem o valor das aulas presenciais, da Universidade e das atividades que ela promovia, inclusive as que vem promovendo através do mundo virtual durante a pandemia. 
Devemos atentar aos momentos que temos, eu costumava reclamar das tarefas que tinha de fazer, as que precisava sair de casa e agora fico procurando sair de casa para realizar as tarefas, mas não pode, pois é momento de ficar em casa. A pandemia veio para mostrar que temos que valorizar o que temos e as pessoas (ISA).

Eu estudo e estou fazendo cursos para ocupar o tempo e fazendo leituras para a escrita do TCC. [...] Sinto falta dos colegas, mesmo tendo colegas tão próximos aqui na comunidade, com a pandemia ficaram distantes devido ao isolamento.Aprendi que tem coisas que eu achava que eram essenciais, mas que hoje vejo que não é essencial. Aprendi que tenho que valorizar mais a minha família, amigos (LPG).

Estou valorizando mais os momentos com minha família, [...] estou sentindo falta dos colegas. A pandemia veio mostrar que tudo é no seu tempo e que as pessoas dependem uma das outras. Devemos valorizar o momento [...](VTM).

Estou dando mais valor a minha família as pequenas coisas e principalmente a valorizar o próximo (JNB).

Estes diferentes relatos reforçam o que diz Santos (2020) ao afirmar que: "O vírus é um professor no sentido de que ele está nos dando várias lições”. Nesta direção, compartilhamos com a perspectiva de Paulo Carrano (2003), quando trata do espaço como um campo de possibilidades educativas. Para o autor, no movimento da práxis social muitos processos formativos podem ocorrer e eles se dão de maneira continua e descontinua, previsível e imprevisíl, homogênea e heterogênea. Associado aos mecanismos e ritos formalizados para conceber e gerar aprendizagens, vivenciamos no cotidiano situações que não foram previstas para serem educativas, mas acabam gerando efeitos educativos.

Contribuindo com essa reflexão, Charlot (2005), dialoga sobre a relação dos jovens com o saber, afirmando que:" "A relação com o saber é a relação com o mundo, com o outro e consigo mesmo de um sujeito confrontado com a necessidade de aprender”(CHARLOT, 2005, p.45). A relação com o saber é o conjunto de relações que um sujeito estabele com um objeto, com um conteúdo, um lugar, uma pessoa dentre tantas situações promissoras de aprendizagens.

Nas vozes dos estudantes esta relação com o saber fica evidente e demarca o que aprendem e nos ensinam com o conjunto de relações estabelecidas no cenário em que enfrentam a pandemia. Neste contexto pandêmico, a pesquisa autobiográfica pode nos fornecer pistas que nos ajudem no entendimento das contradições, desafios e potências próprias destes estudantes, que já têm suas histórias de vidas marcadas pela resistência e persistência para se inserir socialmente.

No que diz respeito às expectativas da vida pós-pandemia, as incertezas dos jovens revelam uma realidade que é impossível de ser negada: a tensão e o medo gerado pelas condições de existência e sobrevivência no retorno à universidade após a pandemia do novo coronavírus. Isso revela o quanto as populações negras e pobres do campo sãoatingidas mais duramente, já que "[...]a perversidade da imbricação entre capitalismo, racismo e desigualdade opera em momentos específicos da nossa história, como é o caso das pandemias”(GOMES 2020, p.07).

LPG, relata que: "Já pensei várias vezes no retorno e tive pesadelos, estou vivendo em um mundo de incertezas”. LPG, diz que: “As expectativas são muitas, mas têm as incertezas.” E JGB fala que: "Para o retorno na Universidade.... fico pensando em como vai ser esse retorno, será que quando voltar vai ter a vacina?” MAS expressa o desejo "[...] que tudo acabe logo e que todos voltem com saúde e consigam se formar para poder trabalhar e seguir a vida”. Já JGB sinaliza: "Espero voltar logo e que eu possa valorizar mais a Universidade enquanto espaço de conquista e resistência”. 
Apesar das dúvidas e incertezas, todos potencializam sentimento de querer que tudo isso acabe logo e que todos voltem com saúde e valorizem o espaço da Universidade. São relatos que expressam a capacidade de auto reflexão dos jovens e o reconhecimento do valor da Universidade para suas vidas, mas são também narrativas perpassadas pelo temor causado aos ataques à direitos conquistados nas últimas décadas: o direito de poder se alimentar com mais dignidade, de ter condições dignas de moradia, de sonhar com o acesso à Universidade e muitos outros.

No Brasil, as populações pauperizadas vivenciam o isolamento social por dentro de outro isolamento social, uma vez que, antes da pandemia, as desigualdades sociais já isolavam os pobres, em sua maioria negros, dos bens e serviços indispensáveis à dignidade humana. Segundo Gomes (2020, p.02), essa realidade é“[...] fruto de uma perversidade histórica e estrutural ativamente produzida que, no contexto de exacerbação do neoliberalismo e da crise sanitária, revela a imbricação entre raça, pobreza, saúde pública e Estado.”

É perceptível nos relatos dos jovens, ao falarem sobre suas expectativas, a insegurança gerada pela ausência de políticas públicas sociais e pelas desigualdades que marcam o cotidiano dos jovens camponeses, na sua maioria negros e negras, devastados pelas consequências da inexistência de uma ação efetiva do Estado para diminuir as desigualdades e do racismo estrutural que impera na sociedade brasileira.

Nesse sentido, este estudo com jovens universitários camponeses surge também como tentativa de romper com a situação de pouca visibilidade destes estudantes nos estudos acadêmicos, apostando na potência dos saberes, resistência e persistência destes jovens. À Universidade cabe aprender com os saberes acionados pelos jovens camponeses e suas reações e modos de (re)construção da existência em meio a tantas situações adversas. Isso perpassa pela sensibilidade das instituições em repensar seus planejamentos, entendendo que não podemos ignorar os efeitos da pandemia para os estudantantes e as inúmeras estratégias utilizadas por eles para se fortalecerem e continuar aprendendo, defendendo o direito à vida digna, o que inclui também o direito de permanência na universidade.

\section{CONSIDERAÇÕES FINAIS}

O jovem, em seu processo de desenvolvimento, constrói sua identidade no entrecruzamento das condições pessoais, culturais, sociais, econômicas e históricas nas quais está inserido. A complexidade desse processo traz à tona a importância de estudos que revelem as condições de construção de projetos de vida juvenis. No que diz respeito às investigações sobre a temática das juventudes do campo, entendemos que há muito a ser percorrido no sentido de nos aproximarmos destes jovens, procurando entender melhor os desafios e potencialidades que permeiam seus modos de ser e existir.

O estudo revelou pistas importantes para entendermos melhor os jovens estudantes do campo, suas culturas, o modo como compreendem o trabalho, a educação, as relações sociais, dentre outros, facilitando-nos na construção de encaminhamentos pedagógicos em consonância com estes indicadores. As narrativas também foram relevantes para entendermos e propormos subsídios de enfrentamento das questões da permanência na Universidade, no período pós-pandemia, quando teremos sujeitos diferentes, em um cenário que não será mais o mesmo.

Por fim, retratamos aqui a complexidade de vivências juvenis no contexto da pandemia, ressaltando a importância de estudos e pesquisas que escutem os jovens universitários do campo, visto que é através desta escuta que se tem a oportunidade de evidenciar o contexto social destes jovens, de discutir possibilidades para a permanência destes na universidade, em um cenário mais justo e igualitário. 


\section{REFERÊNCIAS}

BOURDIEU, Pierre (Org.). A miséria do mundo. 6a ed. Trad.Mateus S. S. Azevedo, Jaime A. Clasen et al. Petrópolis, RJ: Vozes, 2007.

BORGHI, Idalina S. Mascarenhas. Uma Margem Outra: itinerâncias de jovens das classes populares na educação superior. Tese de doutorado - Faculdade de Educação, UFBA, Salvador, 2013.

CARRANO, PAULO. Os múltiplos “eus” dos adolescentes: juventudes, as identidades são múltiplas. Século XXI, Rio de Janeiro: Portal Multirio, 2007. Capturado em 02/04/2013. Disponível em < http://portalmultirio.rio. rj.gov.br/sec21/chave_artigo.asp?cod_artigo=1086 >.

CHARLOT, Bernard (org.) Os jovens e o saber: perspectivas mundiais, trad. fátimamurad. - Porto Alegre: Artmed, 2001.

CALDART, Roseli Salete. Concepção de Educação do Campo. In. MOLINA, Mônica Castagna; Martins Fátima Almeida [orgs.]. Formação de Formadores: Reflexões sobre as experiências da Licenciatura em Educação do Campo no Brasil.1. ed. - Belo Horizonte, MG: Autêntica Editora, 2019, p.55-75.

DAYRELL, Juarez. A juventude no Brasil. Serviço Social da Indústria (SESI), n. 30, p. 25- 39, dez. 1999. Capturado em 30/03/2013. Disponível em http://www.cmjbh.com.br/arq_Artigos/SESI\%20JUVENTUDE\%20 NO\%20BRASIL.pdf.

DELORY-MOMBERGER. Christine. Biografia e Educação: figuras do indivíduo-projeto. Tradução e revisão científica: Maria da Conceição Passeggi, João Gomes da Silva Neto, LuisPasseggi. - $2^{\text {a }}$ ed. - Natal/RN: EDUFRN, 2014.

GOMES, Nilma Lino. A questão racial e o novo coronavírus no Brasil. Trabalho e Justiça Social. Junho/2020. Disponível em: http://library.fes.de/pdf-files/bueros/brasilien/16315.pdf. Acesso em 05/07/2020.

KAMMSETZER, Christiane Silveira e PALOMBINI, Analice de Lima.Território e Subjetividade: narrativas de jovens em uma remoção urbana. Fractal, Rev. Psicol. 2017, vol.29, n.3, pp.280-287. ISSN 1984-0292. http:// dx.doi.org/10.22409/1984-0292/v29i3/1427. Acesso em 30/06/2019.

LEMINSKI, Paulo. Toda Poesia. São Paulo: Companhia das Letras, 2013.

NOGUEIRA, Fábio. Governo Temer como restauração colonialista. Le Monde Diplomatique Brasil, Rio de Janeiro, p. 4-5, 9 jan. 2017.

PAIS, José Machado. Culturas Juvenis. 2ª ed. Lisboa: Imprensa Nacional, Casa da Moeda, 2003.

SANTOS, Boaventura de Sousa. A Cruel Pedagogia do Vírus. Coimbra: Edições Almeida S. A, 2020. 